\title{
Development of sorting methods based on physical and aerodynamic properties of off-ground harvested almonds
}

\author{
Chang Chen ${ }^{1}$, Ragab Khir ${ }^{1,2}$, Rentang Zhang ${ }^{1,3}$, Xiangyu Cao ${ }^{1,4}$, Zhaokun Ning ${ }^{1}$, Yi Shen ${ }^{1}$, \\ Tianxin Wang ${ }^{1,5}$, Zhongli Pan ${ }^{1 *}$ \\ (1. Department of Biological and Agricultural Engineering, University of California, Davis, CA 95616, USA; \\ 2. Department of Agricultural Engineering, Faculty of Agriculture, Suez Canal University, Ismailia 41522, Egypt; \\ 3. College of Food Science and Engineering, Shandong Agricultural University, Tai'an 271018, Shandong, China; \\ 4. School of Life Science, Liaoning University, Shenyang 110036, China; \\ 5. State Key Laboratory of Food Nutrition and Safety, Tianjin University of Science and Technology, Tianjin 300457, China)
}

\begin{abstract}
This research was conducted to develop an effective approach to sort off-ground harvested almonds for efficient drying based on their physical and aerodynamic properties. Three popular varieties were studied, including Nonpareil, Monterey, and Fritz. The insect damage, axial dimensions, weight ratio, moisture content, bulk density and terminal velocity of in-hull almonds, in-shell almonds and loose hull at harvest were measured. The results indicated that the insect infestation percentage in the off-ground harvested almonds ranged from $2.5 \%$ to $6.3 \%$, which was about half of those in the conventional on-ground dried almonds. Loose hulls and in-hull almonds had higher moisture content and wider moisture distribution than those of in-shell almonds, suggesting that sorting of the almonds and drying them separately are necessary for efficient handling and processing. Thickness was the smallest axial dimension of an almond, and thus could be used for sorting. The cut-off sizes of $16.5 \mathrm{~mm}$, $21.3 \mathrm{~mm}$ and $21.1 \mathrm{~mm}$ could separate $100 \%$ of the in-shell almonds from the rest for Nonpareil, Monterey and Fritz varieties, respectively, as the first step. In the second step, applying terminal velocities of $12.3 \mathrm{~m} / \mathrm{s}, 11.8 \mathrm{~m} / \mathrm{s}$ and $12.2 \mathrm{~m} / \mathrm{s}$ could efficiently separate the in-hull almonds and loose hulls for Nonpareil, Monterey and Fritz varieties, respectively. Overall, up to $76.7 \%$ of the loose hulls could be removed, and up to 3.3\% in-hull almonds may be lost during the sorting process. The experimental results provided important information for developing efficient sorting and drying methods with improved throughput, energy efficiency, better quality and safety of off-ground harvested almonds.
\end{abstract}

Keywords: almond, off-ground harvesting, physical properties, aerodynamic properties, sorting, drying DOI: $10.25165 /$ j.ijabe.20211402.6090

Citation: Chen C, Khir R, Zhang R T, Cao X Y, Ning Z K, ShenY, et al. Development of sorting methods based on physical and aerodynamic properties of off-ground harvested almonds. Int J Agric \& Biol Eng, 2021; 14(2): 218-225.

\section{Introduction}

California produces around $1150000 \mathrm{t}$ of almonds annually, which represents around $80 \%$ of the total almond production in the world $\mathrm{d}^{[1,2]}$. The typical almond harvest operations in California include shaking, on-ground natural drying, sweeping, and picking up $^{[3]}$. The current harvest method has two major problems: one is a large amount of dust generation during the sweeping and picking up processes, which causes air pollution and impacts the health of millions of people; the other one is that the almonds spend a long time on the orchard floor during the on-ground natural drying, which

Received date: $2020-08-18 \quad$ Accepted date: $2020-10-20$

Biographies: Chang Chen, $\mathrm{PhD}$, Postdoctoral fellow, research interest: food processing engineering, Email: cgchen@ucdavis.edu; Ragab Khir, PhD, Research Scientist, research interest: food processing engineering, Email: rgebreil@ucdavis.edu; Rentang Zhang, PhD, Associate Professor, research interest: food nutrition and processing, Email: rentangzhang@163.com; Xiangyu Cao, PhD, Associate Professor, research interest: food nutrition, Email: phdcao@ucdavis.edu; Zhaokun Ning, MS, Graduate student, research interest: food processing engineering, Email: zning@ucdavis.edu; Yi Shen, PhD, Postdoctoral fellow, research interest: food processing engineering, Email: yishen@ucdavis.edu; Tianxin Wang, PhD, Associate Professor, research interest: food processing engineering, Email: txnwang@ucdavis.edu.

*Corresponding author: Zhongli Pan, PhD, Professor, research interest: food processing engineering 3018 Bainer Hall, University of California, Davis, One Shields Avenue, Davis, CA 95616, USA. Tel: +1-530-752-4367, Email: zlpan@ucdavis.edu. introduces a pathway for severe insect infestation (for example, navel-orange worm) and contamination by aflatoxin-producing molds ${ }^{[4,5]}$. Schatzki and Ong ${ }^{[6]}$ found correlations between the incidence of aflatoxin and the level of insect damage.

To resolve the aforementioned problems, the Almond Board of California and the almond industry are committed to seeking new harvesting and drying technologies. The off-ground harvesting method using a catch-frame is considered a better alternative for almonds to mitigate dust generation, microbial contamination and insect damage. However, the almonds harvested with the new method have high moisture content (MC) and thus need to be dried artificially to handle the large production volume in a short season to ensure quality and safety.

Hot air (HA) drying with deep bed dryers is one of the most commonly used drying technology for tree nuts due to its large drying capacity ${ }^{[7-9]}$. The MCs of tree nuts usually vary in a wide range ${ }^{[10-13]}$, thus drying nuts with mixed MCs may cause non-uniform drying and associated problems ${ }^{[14,15]}$. The high moisture nuts may be under-dried, which causes food safety concerns. To ensure the safety of the nuts, the drying time is usually intentionally extended, which may result in over-drying of low moisture nuts and inevitably cause quality deterioration and waste of energy ${ }^{[16]}$. The individual almonds at harvest are normally at different maturity levels, and their MCs vary in a wide range. Chen et al. ${ }^{[9]}$ studied the energy consumption of the almond drying process with a pilot-scale HA column dryer, and found that more 
than $60 \%$ of the total energy input was used for drying the almond hulls and only about $20 \%$ of the total energy was used to dry the kernels. Therefore, drying of mixed almonds containing different fractions (in-hull almonds, in-shell almonds and loose hulls) was considered inefficient. Therefore, this research tried to develop sorting methods to sort the almond mixture into in-hull almonds, in-shell almonds and loose hulls. Then the in-hull and in-shell almonds can be dried separately, and the hulls do not need to be dried. This approach will improve the drying uniformity and energy efficiency, increase the processing throughput by reducing drying time, and enhance the quality and safety of almonds.

The physical and aerodynamic properties of agricultural products at harvest constitute essential engineering parameters for the design and development of efficient handling and drying technologies ${ }^{[17-19]}$. Particularly, axial dimensions can be important in determining the cut-off sizes for sorting and grading products. The density and MC of tree nuts are highly related to the terminal velocity $^{[20,21]}$, which is useful for the pneumatic sorting of the nuts into different moisture levels. Khir et al. ${ }^{[22]}$ determined the axial dimensions and initial moisture distributions of walnuts harvested at different conditions (with or without hull, different varieties and early or late harvest), and developed regression models to predict the kernel MC based on shell MC. Ozdemir and Akinci ${ }^{[23]}$ determined the dimensions, volume, bulk densities and terminal velocity of four major Turkish hazelnut varieties. Galedar et al. ${ }^{[24]}$ determined the geometric mean diameter, bulk densities and terminal velocities of pistachio nuts and kernels and correlated them with MCs. Aydin ${ }^{[25]}$ studied some physical properties of almond kernels at different moisture levels. Khir et al. ${ }^{[26]}$ determined the terminal velocity of freshly harvested walnuts and found a strong linear relationship $\left(R^{2}>0.90\right)$ between the terminal velocity with the density and MCs. They developed an effective sorting approach for walnuts, named 'air knife' and has been adopted in the industry. However, limited information is available in the literature about the physical and aerodynamic properties of off-ground harvested almonds with different maturity levels that can be used for developing sorting technologies for almonds.

Therefore, the goal of this study was to develop effective sorting methods of off-ground harvested almonds based on their physical and aerodynamic properties. Specific objectives include: (1) to evaluate the effectiveness of off-ground harvesting in mitigation of insect damage; (2) to characterize the physical and aerodynamic properties of in-hull, in-shell almonds, kernels and loose hulls from off-ground harvesting; (3) to study the correlation between the physical and aerodynamic properties with MC of almonds; (4) to develop effective sorting methods for freshly harvested almonds. The findings from this study can provide important information in developing efficient drying methods for off-ground harvested almonds to meet the urgent needs in the industry and to improve processing efficiency, product quality and safety.

\section{Materials and methods}

\subsection{Initial characteristics of almonds}

The almonds of three varieties, including Nonpareil (soft-shell), Monterey (medium hard-shell) and Fritz (hard-shell), were used for conducting this study. The almonds were shaken off from trees about $10 \mathrm{~d}$ earlier than the conventional harvest and collected directly (off-ground) using a catch-frame at Nickels Soil Lab, Arbuckle, CA, USA in the harvest season 2019. Around $500 \mathrm{~kg}$ of almonds of each variety were transported to the Food Processing Laboratory, University of California Davis and processed immediately. Meanwhile, the portions of almonds from the same batch were left on-ground for natural drying and collected later for quality evaluation and comparison. Harvested almonds included three major fractions: in-hull almonds, in-shell almonds, and loose hulls (as shown in Figure 1). The weight ratio of each fraction in the harvested mixture was measured.
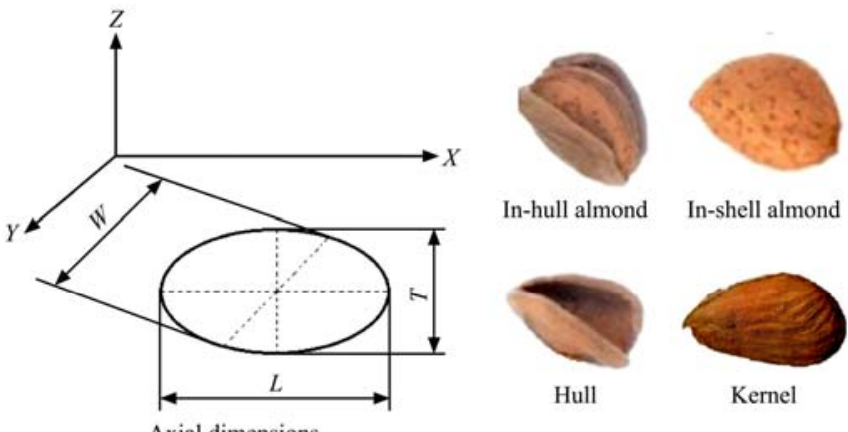

In-shell almond

Axial dimensions

Note: $L$ : the length of almond, $\mathrm{mm} ; W$ : the width of almond, $\mathrm{mm} ; T$ : the thickness of almond, mm.

Figure 1 Axial dimensions and different fractions of off-ground harvested almonds

\subsection{Measurement of insect infestation percentage and bulk density}

For each variety, 150 freshly harvested almonds were randomly selected from the off-ground harvesting and conventional harvesting, respectively. The hulls and shells were carefully opened, and the status of insect infestation was visually evaluated. The numbers and percentage of the insect-infested almonds were recorded and calculated as follows:

$$
Y_{\text {insect }}=\frac{N_{\text {insect, } \text {,in-shell }}+N_{\text {insect, }, \text { in-hull }}}{N_{\text {total }}} \times 100 \%
$$

where, $y_{\text {insect }}$ is the insect infestation percentage, $\% ; N_{\text {insect, } \text {,in-shell }}$ is the number of insect-infested kernels in the in-shell almonds; $N_{\text {insect,in-hull }}$ is the number of insect-infested kernels in in-hull almonds; $N_{\text {total }}$ is the total number of almond kernels.

\subsection{Measurement of axial dimensions and bulk density}

The axial dimensions of the in-hull almonds, in-shell almonds, loose hulls and kernels were measured with a digital caliper (0.01 mm accuracy, KR_001, KRAFTLER) as shown in Figure 1.

The bulk density $\left(\rho_{b}\right)$ is the ratio of the mass sample to its total volume when almonds are stacked in bulk. The bulk densities of almonds were determined using a method that was introduced by Aydin ${ }^{[25]}$. Specifically, a sample of known mass was poured and loosely filled into a container with known volume, and any excess amount was removed. The bulk density was then calculated using Equation (2):

$$
\rho_{b}=\frac{W_{\text {component }, i}}{V}
$$

where, $W_{\text {componet, } i}$ is the mass of the almond samples, $\mathrm{kg} ; V$ is the volume of the container, $\mathrm{m}^{3}$.

\subsection{Moisture content determination and distribution}

To determine the distribution of MCs of each component (kernel, shell and hull) in the freshly harvested almonds, 30 samples of the loose hull, in-hull almonds and in-shell almonds were randomly selected, numbered, broken and then weighed independently. The MC on wet basis (w.b.) of each almond component was measured by drying the samples in an air oven at $105^{\circ} \mathrm{C}$ for $24 \mathrm{~h}^{[22]}$ and calculated using Equation (3):

$$
M C_{w b, i}=\frac{W_{i}-W_{d}}{W_{i}}
$$


where, $W_{i}$ is the initial weight of the almond sample, $\mathrm{kg} ; W_{d}$ is the dry weight of the almond sample, $\mathrm{kg} ; M C_{w b, i}$ is the wet basis $\mathrm{MC}$ of the almond component, $(\mathrm{kg}$ water $) \cdot(\mathrm{kg} \text { wet mass })^{-1}$.

Then, the MC of the whole almonds was calculated as Equation (4):

$$
M C_{w b}=\frac{\left(W_{h i}-W_{h d}\right)+\left(W_{s i}-W_{s d}\right)+\left(W_{k i}-W_{k d}\right)}{\left(W_{h i}+W_{s i}+W_{k i}\right)}
$$

where, $W_{h i}$ is the initial weight of almond hulls, $\mathrm{kg} ; W_{s \mathrm{i}}$ is the initial weight of almond shells, $\mathrm{kg} ; W_{k i}$ is the initial weight of almond kernels, $\mathrm{kg} ; W_{h d}$ is the final weight of almond hulls, $\mathrm{kg} ; W_{s d}$ is the final weight of almond shells, $\mathrm{kg} ; W_{k d}$ is the final weight of almond kernels, $\mathrm{kg}$.

\subsection{Terminal velocity determination}

The terminal velocity of individual almonds was measured in a cylindrical column using a method described by Khir et al. ${ }^{[7]}$. The customized device (Figure 2) was composed of a vertical transparent plastic column with $100 \mathrm{~cm}$ height and $20 \mathrm{~cm}$ diameter. A centrifugal blower (Dayton Electric Mfg. Co.) that produced vertical upward airflow, and a speed amplifier (Dayton Electric Mfg. Co.) was used to control the air speed. The airflow was distributed through an air straightener to ensure uniform airflow distribution, and a perforated screen set at a height of $50 \mathrm{~cm}$ in the column was used as a sample holder. A hot air anemometer (HHF-SD1, Omega, USA, $0.1 \mathrm{~m} / \mathrm{s}$ accuracy) was used to measure the air velocity at where the individual almond was suspended. In each test, an individual almond was placed on the holder, and the terminal velocity was measured as the velocity at which the nut was just lifted off the screen. Three replicate measurements were taken for each almond.

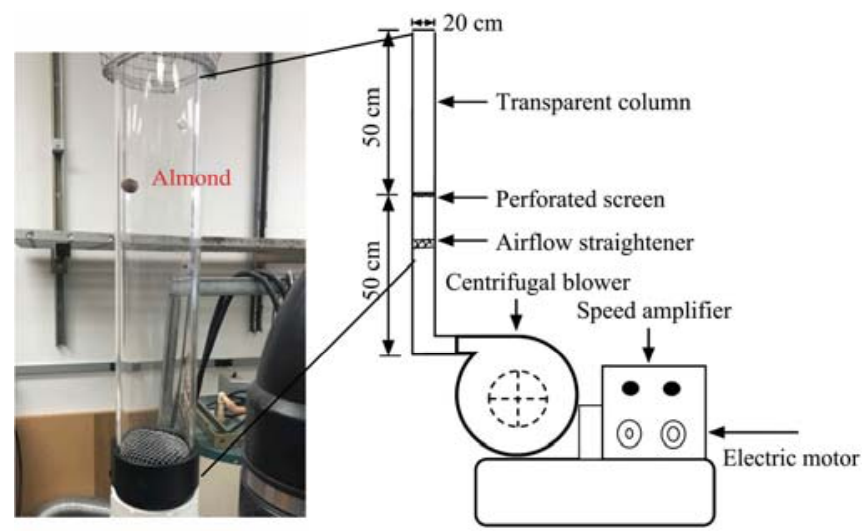

Figure 2 Schematic diagram and photo of terminal velocity measurement device ${ }^{[22]}$

\subsection{Statistical analysis}

The differences in the dimensions, bulk densities and terminal velocities of almonds from the same variety, and the differences in the insect infestation percentages for different varieties and harvesting methods were studied using Tukey test at a confidence level of $95 \%$ by analysis of variance (ANOVA). Linear regression models were used to correlate the MC of overall in-hull almond or in-shell almond with its kernel MC, and the correlation between the thickness and terminal velocity with the MC of the samples. The adjusted coefficient of determination $\left(R_{a d j}{ }^{2}\right)$ and root mean square error (RMSE) were used to evaluate the regression models ${ }^{[27,28]}$ using the linear regression kit in the Origin software (Version 2019, OriginLab Corporation, Northampton, MA). The statistical values were defined as the following equations:

$$
R_{a d j}^{2}=1-\frac{\frac{\sum_{i}^{n}\left(R_{e x p, i}-R_{p r e, i}\right)^{2}}{\sum_{i}^{n}\left(\overline{R_{e x p}}-R_{p r e, i}\right)^{2}}(N-1)}{N-p-1}
$$

where, $\rho$ is the number of predictors; $N$ is the total number of samples.

$$
\operatorname{RMSE}=\sqrt{\frac{\sum_{i}^{n}\left(R_{e x p, i}-R_{p r e, i}\right)^{2}}{n}}
$$

where, $R_{\text {exp }, i}$ is the experimental values of the response variables (MC, thickness, or terminal velocity); $R_{p r e, i}$ is the predicted value of the response variables (MC, thickness, or terminal velocity); $\overline{R_{\text {exp }}}$ is the average value of the experimental response variables; $n$ is the number of observations. The values of regression parameters were chosen for the minimization of RMSE and maximization of $R_{a d j}{ }^{2}$.

\section{Results and discussion}

\subsection{Insect infestation percentage, bulk density and weight ratios}

The insect infestation percentage, bulk density and initial weight ratio different fractions of the off-ground harvested and conventionally harvested almonds of each variety are summarized in Table 1. It was found that the insect infestation percentage in the off-ground harvested almonds ranged from $2.5 \%$ to $6.3 \%$, which was about half of those in the on-ground dried almonds (4.5\%-11.4\%). The female insect possibly laid eggs in the split-hull almonds while the nuts were still on the tree. During the on-ground natural drying process, the high moisture almonds spent extended periods on the orchard floor. The suitable air temperature, humidity and soil moisture on the orchard ground facilitated the quick hatching, growing and infestation of destructive insects, and caused serious damage to the kernel meat. Meanwhile, it was found that Monterey variety had more severe insect damage than the other two varieties. Such results might be attributed to that the Monterey variety used in this study was harvested later and spent a longer time

\begin{tabular}{|c|c|c|c|c|c|c|c|c|}
\hline \multirow{2}{*}{ Variety } & \multicolumn{2}{|c|}{ Insect infestation percentage $/ \%{ }^{[\mathrm{a}, \mathrm{c}]}$} & \multicolumn{3}{|c|}{ Bulk density $/ \mathrm{kg} \cdot \mathrm{m}^{-3[\mathrm{~b}]}$} & \multicolumn{3}{|c|}{ Initial weight ratio } \\
\hline & Conventional harvest & Off-ground harvest & Hull & In-shell & In-hull & Hull & In-shell & In-hull \\
\hline Nonpareil & $6.3 \pm 1.1^{\mathrm{B}}$ & $3.3 \pm 0.8^{\mathrm{B}}$ & $240 \pm 23^{\mathrm{bc}}$ & $280 \pm 11^{\mathrm{b}}$ & $330 \pm 25^{\mathrm{a}}$ & $34 \% \pm 5 \%$ & $10 \% \pm 4 \%$ & $56 \% \pm 6 \%$ \\
\hline Monterey & $11.4 \pm 2.6^{\mathrm{A}}$ & $6.3 \pm 1.0^{\mathrm{B}}$ & $200 \pm 19^{\mathrm{c}}$ & $300 \pm 16^{\mathrm{ab}}$ & $310 \pm 26^{\mathrm{a}}$ & $8 \% \pm 4 \%$ & $14 \% \pm 5 \%$ & $78 \% \pm 3 \%$ \\
\hline Fritz & $4.5 \pm 1.0^{\mathrm{BC}}$ & $2.5 \pm 0.5^{\mathrm{C}}$ & $260 \pm 22^{\mathrm{c}}$ & $340 \pm 12^{\mathrm{b}}$ & $390 \pm 20^{\mathrm{a}}$ & $38 \% \pm 6 \%$ & $11 \% \pm 5 \%$ & $51 \% \pm 6 \%$ \\
\hline
\end{tabular}
on the tree.

Table 1 Insect infestation percentage, bulk density, and initial weight ratios of different fractions of almonds

Note: ${ }^{[a]}$ : The insect infestation ratio of each category was measured using 100 randomly selected almonds. ${ }^{[b]}$ : The same lower-case letters denoted that the differences in the bulk densities of almonds from the same variety were not significant at $p<0.05 .{ }^{[\mathrm{c}]}$ : The same upper-case letters denoted that the differences in the insect infestation percentage of almonds were not significant at $p<0.05$.

Bulk density is very important in determining the capacity of drying systems ${ }^{[29]}$. The bulk density of the in-hull almonds, in-shell almonds and loose hulls ranged from 310 to $390 \mathrm{~kg} / \mathrm{m}^{3}, 280$ to
$340 \mathrm{~kg} / \mathrm{m}^{3}$ and 200 to $260 \mathrm{~kg} / \mathrm{m}^{3}$, respectively for the three varieties. These results were in accordance with the findings reported by $\operatorname{Aydin}^{[25]}$ and Mirzabe et al. ${ }^{[30]}$. It was found that the bulk density 
of the Fritz almonds with the smallest length and width was the highest among the three varieties. The weight of in-hull almonds took up more than half of the total harvest weight, and the weight of in-shell almonds was less than $15 \%$. The weight ratio of loose hulls ranged from $8 \%$ to $38 \%$.

Meanwhile, the weight percentages of different components in the in-shell and in-hull almonds for different varieties were determined. For in-shell almonds, the kernel took up 52.2\%-61.8\% and shell took up $47.8 \%-38.2 \%$ of the total weight. For in-hull almonds, the weight percentage of hull, shell and kernel ranged $48.2 \%-65.3 \%, 13.7 \%-24.1 \%$ and $21.0 \%-27.7 \%$, respectively.

\subsection{Moisture characteristics}

\subsubsection{Distribution of initial moisture content}

The frequency distribution plots for the MC of different almond components from different varieties are shown in Figure 3. The moisture distribution curves show good normality with peaks around the average MCs. Some of the curves appear to be skewed to the right, which suggests the presence of samples with relatively high MC.

From Figure 3a, it is found that the MCs of kernel and shell from in-shell almonds of Nonpareil variety range from 0.021 to $0.124 \mathrm{~kg}$ water $/ \mathrm{kg}$ wet mass and 0.039 to $0.125 \mathrm{~kg}$ water $/ \mathrm{kg}$ wet mass, respectively. Meanwhiles, the MC of kernel, shell and hull from in-hull almonds range from 0.002 to $0.246 \mathrm{~kg}$ water $/ \mathrm{kg}$ wet mass, 0.004 to $0.195 \mathrm{~kg}$ water $/ \mathrm{kg}$ wet mass and 0.025 to $0.500 \mathrm{~kg}$ water $/ \mathrm{kg}$ wet mass, respectively. The MCs of loose hulls range from 0.150 to $0.360 \mathrm{~kg}$ water $/ \mathrm{kg}$ wet mass. Similar distribution patterns are observed for Monterey (Figure 3b) and Fritz varieties (Figure 3c).

For Monterey variety, the MCs of kernel and shell from in-shell almonds range from 0.005 to $0.325 \mathrm{~kg}$ water $/ \mathrm{kg}$ wet mass and 0.039 to $0.172 \mathrm{~kg}$ water $/ \mathrm{kg}$ wet mass, respectively. The MCs of kernel, shell and hull from in-hull almonds ranged from 0.003 to $0.293 \mathrm{~kg}$ water $/ \mathrm{kg}$ wet mass, 0.016 to $0.285 \mathrm{~kg}$ water $/ \mathrm{kg}$ wet mass and 0.001 to $0.519 \mathrm{~kg}$ water $/ \mathrm{kg}$ wet mass, respectively. The MCs of loose hulls range from 0.178 to $0.360 \mathrm{~kg}$ water $/ \mathrm{kg}$ wet mass.

For Fritz variety, the MCs of kernel and shell from in-shell almonds range from 0.013 to $0.178 \mathrm{~kg}$ water $/ \mathrm{kg}$ wet mass and 0.054 to $0.152 \mathrm{~kg}$ water $/ \mathrm{kg}$ wet mass, respectively. The MCs of kernel, shell and hull from in-hull almonds ranged from 0.003 to $0.402 \mathrm{~kg}$ water $/ \mathrm{kg}$ wet mass, 0.025 to $0.326 \mathrm{~kg}$ water $/ \mathrm{kg}$ wet mass and 0.010 to $0.557 \mathrm{~kg}$ water $/ \mathrm{kg}$ wet mass, respectively. The MCs of loose hulls range from 0.191 to $0.326 \mathrm{~kg}$ water $/ \mathrm{kg}$ wet mass. Although the average kernel MCs were similar in the three varieties, the MC distribution of Fritz variety was wider compared to that of the other two varieties.

The obtained results clearly showed that the MCs of kernel and shell in the in-hull almonds were much higher than those in the in-shell almonds at harvest, and the MC distribution of in-hull almonds was also much wider than the in-shell almonds. Meanwhile, the moisture distribution of loose hulls was narrower than the hull from in-hull almonds. The MC of almond hull was much higher than the shell and kernel. At the same time, it was observed that the MC of shell was higher than the kernel in both the in-shell and in-hull almonds. Based on these moisture distribution characteristics, if the in-hull almonds and in-shell almonds are to be dried together in a mix, the MC of the final products will not be uniform. The high moisture in-hull almonds may be under-dried, causing food safety issues. The low moisture in-shell almonds may be over-dried, resulting in quality deterioration and energy waste. Therefore, the in-hull and in-shell almonds should be separated and dried separately in order to improve the moisture uniformity in the product with ensured quality and safety.
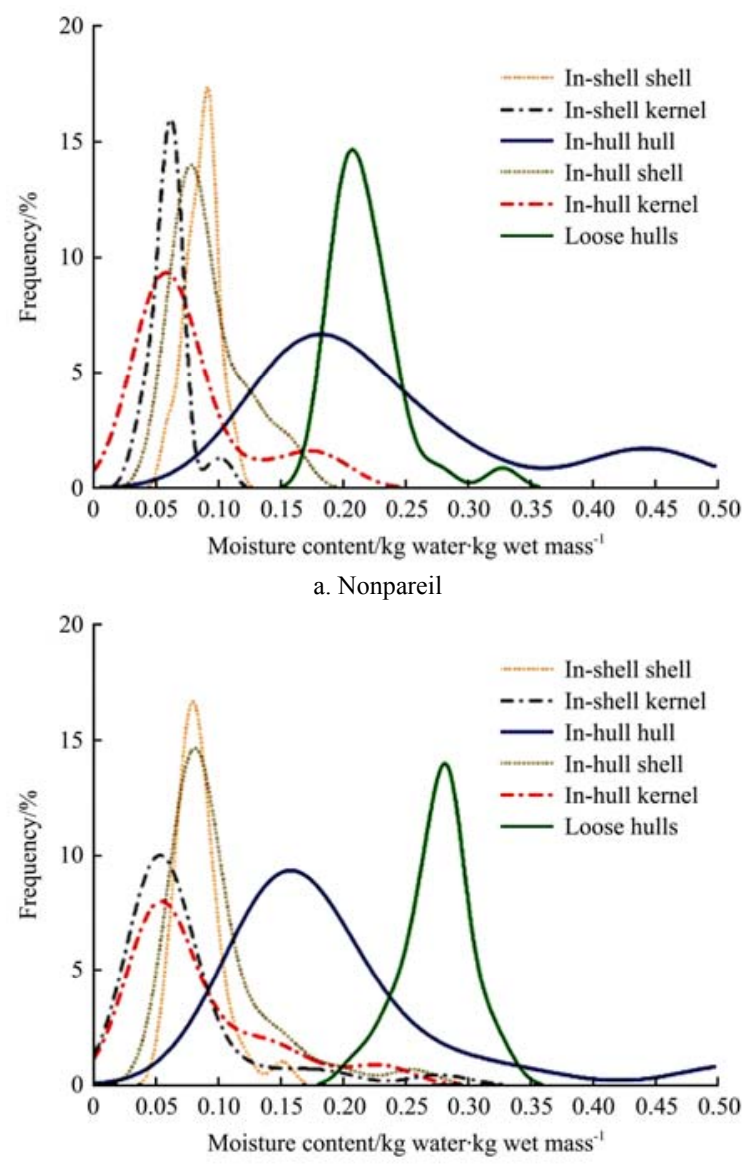

b. Monterey

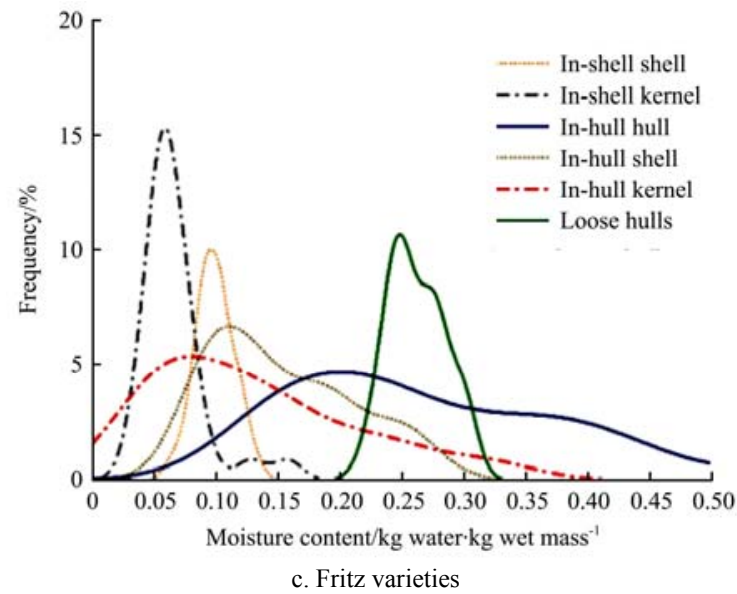

Figure 3 Initial moisture content distributions (wet basis) of almond components for Nonpareil, Monterey and Fritz varieties

In addition, since the MCs of hulls and shells were higher than the MC of kernels, it may be practical to use high temperature heating to rapidly increase the almond temperature and partially remove moisture from almond shell and hull without affecting the product quality ${ }^{[14]}$. As a result, the drying time and energy consumption of the drying process may be reduced ${ }^{[28]}$. Additionally, it was found that the initial weight of the loose hulls and hulls from the in-hull almonds took up around $60 \%$ of the entire almond weight (Table 1). Therefore, separating the loose hulls and de-hulling the in-hull almonds before the drying should significantly reduce the space and cost needed for the handling, transportation and drying, as well as reduced energy needed for the drying process.

3.2.2 Correlation between the whole almond $\mathrm{MC}$ and kernel MC

Estimation of the MC of almond kernels based on the overall 
$\mathrm{MC}$ of whole almonds is important for determining the appropriate drying conditions. The overall $\mathrm{MC}$ of in-shell and in-hull almonds and corresponding kernel $\mathrm{MC}$ for the three varieties are plotted in Figure 4. The correlations between the overall MC of almonds and the kernel MC were determined using regression analysis (Table 2). The results showed that there were strong linear correlations between the overall almond moisture and kernel moisture, the $R_{a d j}{ }^{2}$ ranged from 0.796 to 0.985 for different varieties. Monterey almonds showed the highest correlation, while Fritz almonds had the least correlation, which may be attributed to the wider distribution of the MC in the Fritz walnuts. The regression models that are shown in Table 2 can be used to predict the range of kernel moisture as dependent on the overall almond moisture.

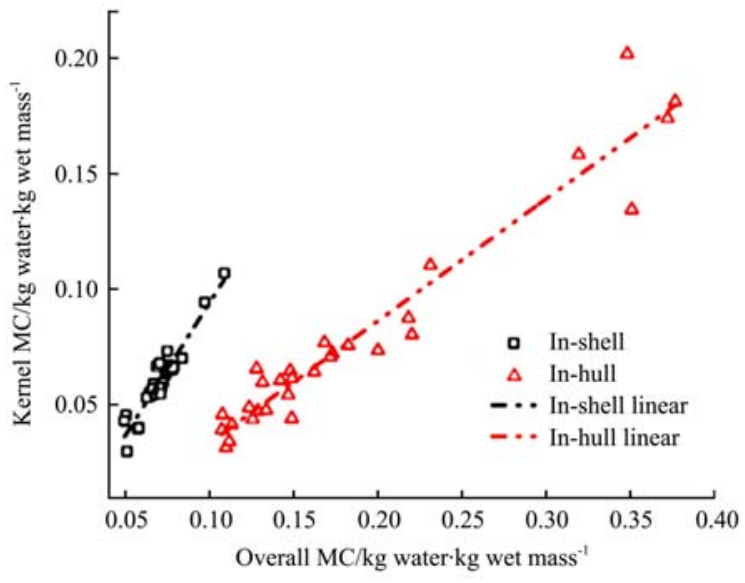

a. Nonpareil

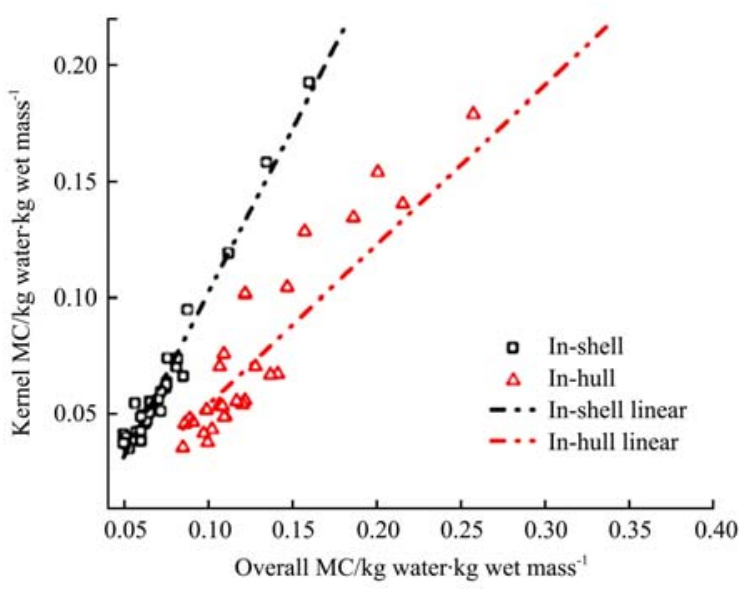

b. Monterey

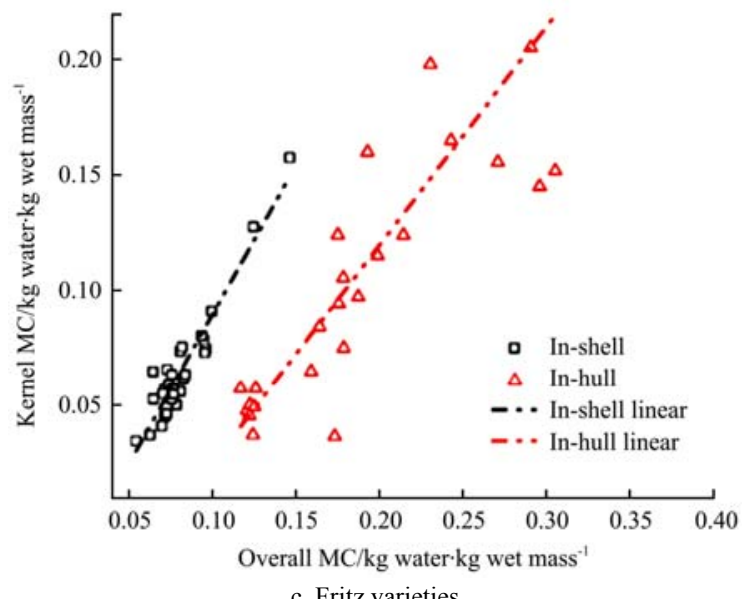

Figure 4 Correlation between the overall moisture content (wet basis) of in-hull and in-shell almonds and corresponding kernel moisture for Nonpareil, Monterey and Fritz varieties
Table 2 Correlation between the MCs of overall almonds and corresponding kernel MCs

\begin{tabular}{ccccc}
\hline Variety & Fraction & Regression equation & $R_{a d j}{ }^{2}$ & RMSE \\
\hline \multirow{2}{*}{ Nonpareil } & In-hull & $\mathrm{MC}_{\text {kernel }}=1.146 \times \mathrm{MC}_{\text {in-hull-0.020 }}-0.902$ & 0.00467 \\
& In-shell & $\mathrm{MC}_{\text {kernel }}=0.527 \times \mathrm{MC}_{\text {in-shell }}-0.019$ & 0.932 & 0.01194 \\
\hline \multirow{2}{*}{ Monterey } & In-hull & $\mathrm{MC}_{\text {kernel }}=1.408 \times \mathrm{MC}_{\text {in-hull }}-0.038$ & 0.985 & 0.00647 \\
& In-shell & $\mathrm{MC}_{\text {kernel }}=0.687 \times \mathrm{MC}_{\text {in-shell }}-0.012$ & 0.912 & 0.01624 \\
\hline \multirow{2}{*}{ Fritz } & In-hull & $\mathrm{MC}_{\text {kernel }}=1.295 \times \mathrm{MC}_{\text {in-hull }}-0.040$ & 0.895 & 0.00806 \\
& In-shell & $\mathrm{MC}_{\text {kernel }}=0.948 \times \mathrm{MC}_{\text {in-shell }}-0.070$ & 0.796 & 0.03660 \\
\hline
\end{tabular}

\subsection{Dimensional characteristics}

The average values and standard deviations of the axial dimensions of loose hulls, in-hull almonds, in-shell almonds and corresponding kernels for the three varieties are summarized in Table 3 .

Table 3 Average and standard deviation of different fractions of fresh-harvested almonds

\begin{tabular}{clccc}
\hline \multirow{2}{*}{ Variety } & Category & \multicolumn{3}{c}{ Dimension $/ \mathrm{mm}^{[\mathrm{a}]}$} \\
\cline { 3 - 5 } & & Length $(L)$ & Width $(W)$ & Thickness $(T)$ \\
\hline \multirow{4}{*}{ Nonpareil } & In-hull & $37.5 \pm 2.7^{\mathrm{a}}$ & $28.0 \pm 2.5^{\mathrm{b}}$ & $23.6 \pm 4.4^{\mathrm{bc}}$ \\
& In-shell & $33.6 \pm 2.4^{\mathrm{ab}}$ & $21.8 \pm 1.9^{\mathrm{bc}}$ & $13.8 \pm 1.2^{\mathrm{c}}$ \\
& Kernel & $24.5 \pm 1.6^{\mathrm{bc}}$ & $13.9 \pm 1.2^{\mathrm{c}}$ & $7.0 \pm 0.5^{\mathrm{d}}$ \\
& Loose hull & $38.1 \pm 2.6^{\mathrm{a}}$ & $27.3 \pm 4.2^{\mathrm{b}}$ & $23.7 \pm 7.1^{\mathrm{bc}}$ \\
\hline \multirow{4}{*}{ Monterey } & In-hull & $38.3 \pm 3.2^{\mathrm{a}}$ & $24.8 \pm 2.3^{\mathrm{b}}$ & $23.2 \pm 2.0^{\mathrm{b}}$ \\
& In-shell & $38.0 \pm 3.0^{\mathrm{a}}$ & $22.2 \pm 1.5^{\mathrm{b}}$ & $17.4 \pm 1.4^{\mathrm{c}}$ \\
& Kernel & $24.9 \pm 3.3^{\mathrm{b}}$ & $13.7 \pm 1.8^{\mathrm{c}}$ & $8.3 \pm 0.7^{\mathrm{d}}$ \\
& Loose hull & $40.2 \pm 3.0^{\mathrm{a}}$ & $24.8 \pm 4.4^{\mathrm{b}}$ & $24.3 \pm 3.8^{\mathrm{b}}$ \\
\hline \multirow{3}{*}{ Fritz } & In-hull & $35.9 \pm 2.7^{\mathrm{a}}$ & $24.1 \pm 2.5^{\mathrm{b}}$ & $24.5 \pm 2.5^{\mathrm{b}}$ \\
& In-shell & $32.5 \pm 2.7^{\mathrm{ab}}$ & $20.3 \pm 1.6^{\mathrm{c}}$ & $17.2 \pm 1.3^{\mathrm{d}}$ \\
& Kernel & $21.9 \pm 1.7^{\mathrm{bc}}$ & $12.5 \pm 1.1^{\mathrm{e}}$ & $8.6 \pm 1.2^{\mathrm{f}}$ \\
& Loose hull & $36.3 \pm 3.0^{\mathrm{a}}$ & $22.7 \pm 6.1^{\mathrm{bc}}$ & $28.3 \pm 7.9^{\mathrm{ab}}$ \\
\hline
\end{tabular}

Note: ${ }^{[a]}$ : The same lower-case letters denoted that the differences in the dimensions of almonds from the same variety were not significant at $p<0.05$.

The results indicated that almonds of different varieties had different dimension characteristics. In general, the size of Fritz almonds was the smallest, and the size of Monterey almonds was the largest. As expected, the axial dimensions $(L, W$ and $T)$ of the in-hull almonds were larger than those of in-shell almonds and kernels, and the size of loose hulls was similar to in-hull almonds. Taking Nonpareil variety as an example, the average length of in-hull almonds, in-shell almonds and loose hulls were $37.5 \mathrm{~mm}$, $33.6 \mathrm{~mm}$ and $38.5 \mathrm{~mm}$, respectively; the average width of in-hull almonds, in-shell almonds and loose hulls were $28.0 \mathrm{~mm}, 21.8 \mathrm{~mm}$ and $27.3 \mathrm{~mm}$, respectively; and the average thickness of in-hull almonds, in-shell almonds and loose hulls were $23.6 \mathrm{~mm}, 13.8 \mathrm{~mm}$ and $23.7 \mathrm{~mm}$, respectively. Similar trends were observed in the other two varieties. It was found that the thickness $(\mathrm{T})$ was the smallest among the three axial dimensions, and the thickness of the in-shell almonds was significantly $(p<0.05)$ smaller than that of the loose hulls and in-hull almonds. Therefore, the thickness of the almonds could be selected as cut-off sizes for separating the in-shell almonds from the loose hulls and in-hull almonds. The sorting visibility based on the dimensional characteristics of almonds is discussed in Section 3.6

\subsection{Terminal velocity}

The values of terminal velocity (TV) of individual almonds from the off-ground harvest are summarized in Table 4, and the frequency distribution plots of TVs are shown in Figure 5. 
Table 4 Range and average values of terminal velocities of fresh-harvested almonds

\begin{tabular}{clcc}
\hline \multirow{2}{*}{ Variety } & \multicolumn{1}{c}{ Category } & \multicolumn{2}{c}{ Terminal velocity $/ \mathrm{m} \cdot \mathrm{s}^{-1}$} \\
\cline { 3 - 4 } & & Range & Average \pm Standard deviation ${ }^{[\mathrm{a}]}$ \\
\hline \multirow{2}{*}{ Nonpareil } & In-hull almond & $10.93-18.60$ & $13.99 \pm 1.30^{\mathrm{a}}$ \\
& In-shell almond & $9.66-12.58$ & $11.16 \pm 0.89^{\mathrm{ab}}$ \\
& Loose hull & $10.01-13.37$ & $11.48 \pm 0.61^{\mathrm{ab}}$ \\
\hline \multirow{2}{*}{ Monterey } & In-hull almond & $11.81-14.49$ & $13.01 \pm 0.67^{\mathrm{a}}$ \\
& In-shell almond & $9.89-12.58$ & $10.94 \pm 0.55^{\mathrm{b}}$ \\
& Loose hull & $8.38-11.70$ & $9.77 \pm 0.71^{\mathrm{b}}$ \\
\hline \multirow{2}{*}{ Fritz } & In-hull almond & $13.06-16.60$ & $14.18 \pm 0.92^{\mathrm{a}}$ \\
& In-shell almond & $11.51-13.76$ & $12.24 \pm 0.50^{\mathrm{ab}}$ \\
& Loose hull & $8.75-11.42$ & $10.09 \pm 0.79^{\mathrm{b}}$ \\
\hline
\end{tabular}

Note: ${ }^{[a]}$ : The same lower-case letters denoted that the differences in the terminal velocities of almonds from the same variety were not significant at $p<0.05$.
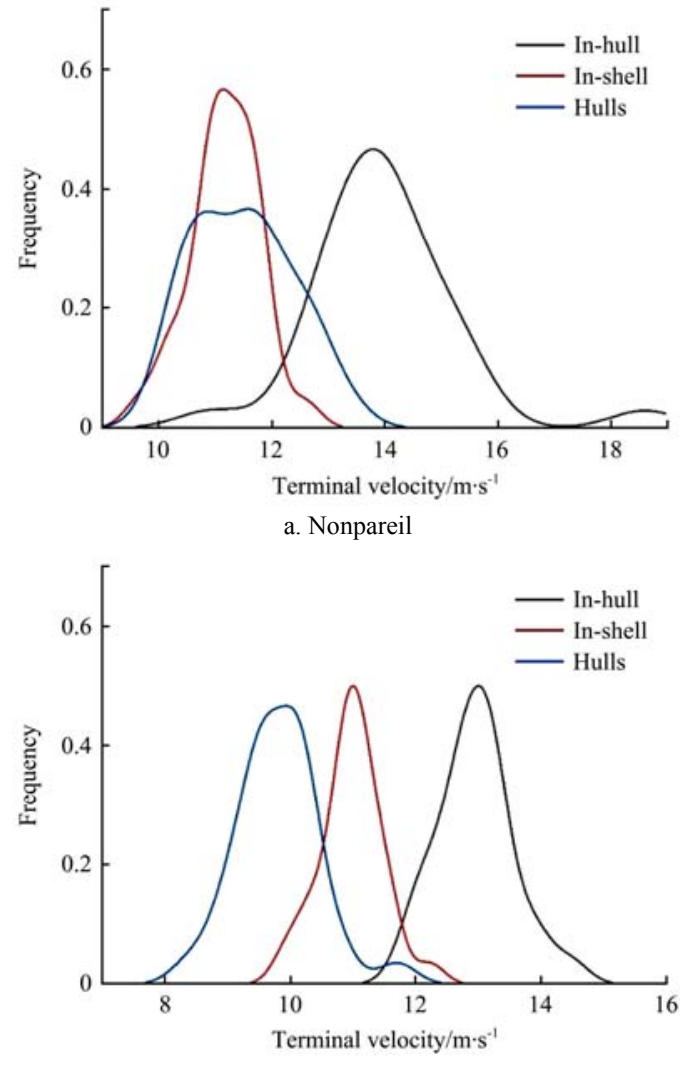

b. Monterey

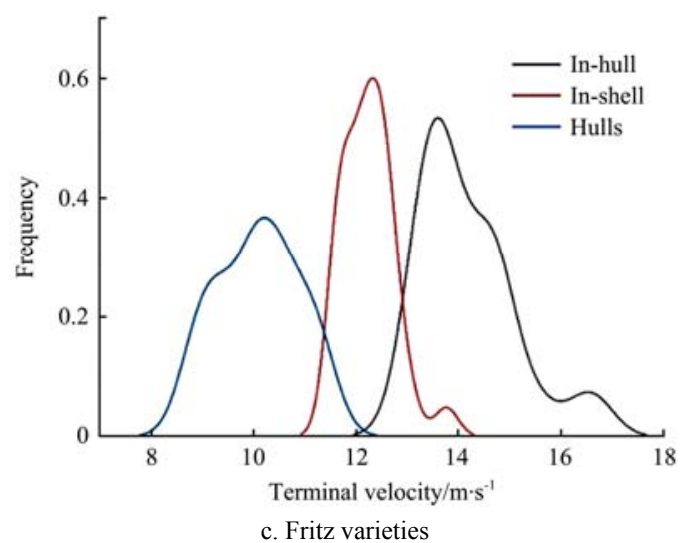

Figure 5 Terminal velocities of different fractions of fresh-harvested almonds for Nonpareil, Monterey and Fritz varieties

It was found that the range of TV of in-hull almonds was much higher than that of the loose hulls, and the overlap was small. It was suggested that the in-hull almonds and loose hulls could be separated based on their difference in the TV. Meanwhile, the TV ranges of in-shell almonds overlapped more with both the other two fractions, particularly for the Nonpareil variety. Therefore, using the TV for sorting as the first step may not be practical, since large portions of in-shell almonds may be misclassified into the other two fractions. Once the in-shell almonds are already separated through size screening, TV can be used as the second step to effectively sort and separate the loose hulls and in-hull almonds.

\subsection{Correlation between axial dimensions and terminal velocities vs. MCs}

The correlations between the almond thicknesses (in-hull almonds, in-shell almonds and loose hulls) and their MCs, and between the terminal velocities and their MCs were also determined using regression analysis. As shown in Figures 6 and 7, no apparent patterns are observed. Meanwhile, the values of $R_{a d j}{ }^{2}$ and RMSE were calculated and summarized in Table 5. It was found that the linear correlations between the thicknesses and MCs of almonds or between the terminal velocities and MCs were not significant $(p<0.05)$, as suggested by the low values of $R_{a d j}{ }^{2}$. The results may be attributed to the degree of the hull opening of individual almonds. Therefore, sorting based on the MCs of almonds may not be feasible. Instead, off-ground harvested almonds should be sorted into different groups (in-hull almonds, in-shell almonds and loose hulls) based on their dimensional characteristics and aerodynamic properties.

Table 5 Correlation between almond thickness and moisture content

\begin{tabular}{cllllll}
\hline \multirow{2}{*}{ Variety } & Fraction & \multicolumn{2}{c}{ Thickness with MC } & & \multicolumn{2}{c}{ Terminal velocity with MC } \\
\cline { 3 - 4 } \cline { 6 - 7 } & & Radj & RMSE & & Radj $j^{2}$ & RMSE \\
\hline \multirow{2}{*}{ Nonpareil } & In-hull & 0.084 & 4.21629 & & 0.270 & 1.11070 \\
& In-shell & 0.030 & 1.19650 & & 0.047 & 0.59603 \\
& Hulls & 0.420 & 5.41521 & & 0.196 & 0.79522 \\
\hline \multirow{2}{*}{ Monterey } & In-hull & 0.047 & 1.94186 & 0.008 & 0.60740 \\
& In-shell & 0.153 & 1.28983 & 0.022 & 0.49217 \\
& Hulls & 0.013 & 4.00148 & 0.010 & 0.65968 \\
\hline \multirow{2}{*}{ Fritz } & In-hull & 0.028 & 2.48147 & 0.002 & 0.93893 \\
& In-shell & 0.013 & 0.25320 & 0.003 & 0.50618 \\
& Hulls & 0.002 & 7.99760 & 0.013 & 0.78829 \\
\hline
\end{tabular}

\subsection{Effectiveness of sorting methods}

The ideal outcome of the sorting is to maximally remove the loose hulls without losing products. At the same time, the in-shell and in-hull almonds should be effectively separated since their MCs are very different and then they can be dried separately. As discussed in the previous sections, size sorting based on almond thickness could be applied as the first step to sort out the in-shell almonds, and then TV sorting could be applied to separate the in-hull almonds and loose hulls.

\subsubsection{Size sorting}

As shown in Figure 6, the thickness of the in-shell almonds was apparently smaller than the majority of the other two fractions, and the distribution range was relatively narrow. Therefore, if the cut-off size of $16.5 \mathrm{~mm}, 21.3 \mathrm{~mm}$ and $21.1 \mathrm{~mm}$ were selected for Nonpareil, Monterey and Fritz varieties, respectively, $100 \%$ of the in-shell almonds could be separated. However, it was also observed that part of the in-hull almonds and loose hulls with small thickness would be mixed into the in-shell almonds. To evaluate the sorting efficacy, the percentages of the misclassification were determined. For Nonpareil, Monterey and Fritz variety, $0 \%$ in-hull 
almonds and $16.7 \%$ loose hulls, $10.0 \%$ of in-hull almonds and $30.0 \%$ of the loose hulls, $6.7 \%$ in-hull almonds and $23.3 \%$ loose hulls would be mixed in the in-shell almonds, respectively. The misclassification percentages were relatively small and should be considered acceptable.

After size sorting, the MCs of in-shell almonds ranged from 0.059 to $0.102 \mathrm{~kg}$ water $/ \mathrm{kg}$ wet mass with an average MC of $0.081 \mathrm{~kg}$ water $/ \mathrm{kg}$ wet mass for Nonpareil variety. For Monterey variety, the MCs of in-shell almonds after sorting ranged from 0.056 to $0.106 \mathrm{~kg}$ water $/ \mathrm{kg}$ wet mass with an average of $0.085 \mathrm{~kg}$ water $/ \mathrm{kg}$ wet mass, and the MCs of misclassified in-hull almonds ranged from 0.185 to $0.210 \mathrm{~kg}$ water $/ \mathrm{kg}$ wet mass. For Fritz variety, the MCs of in-shell almonds after sorting ranged from 0.065 to $0.110 \mathrm{~kg}$ water $/ \mathrm{kg}$ wet mass with an average MC of $0.097 \mathrm{~kg}$ water $/ \mathrm{kg}$ wet mass, and the MCs of misclassified in-hull almonds ranged from 0.200 to $0.222 \mathrm{~kg}$ water $/ \mathrm{kg}$ wet mass. Through the sorting, the moisture ranges of in-shell and in-hull almonds were narrowed compared to the almond mixture.
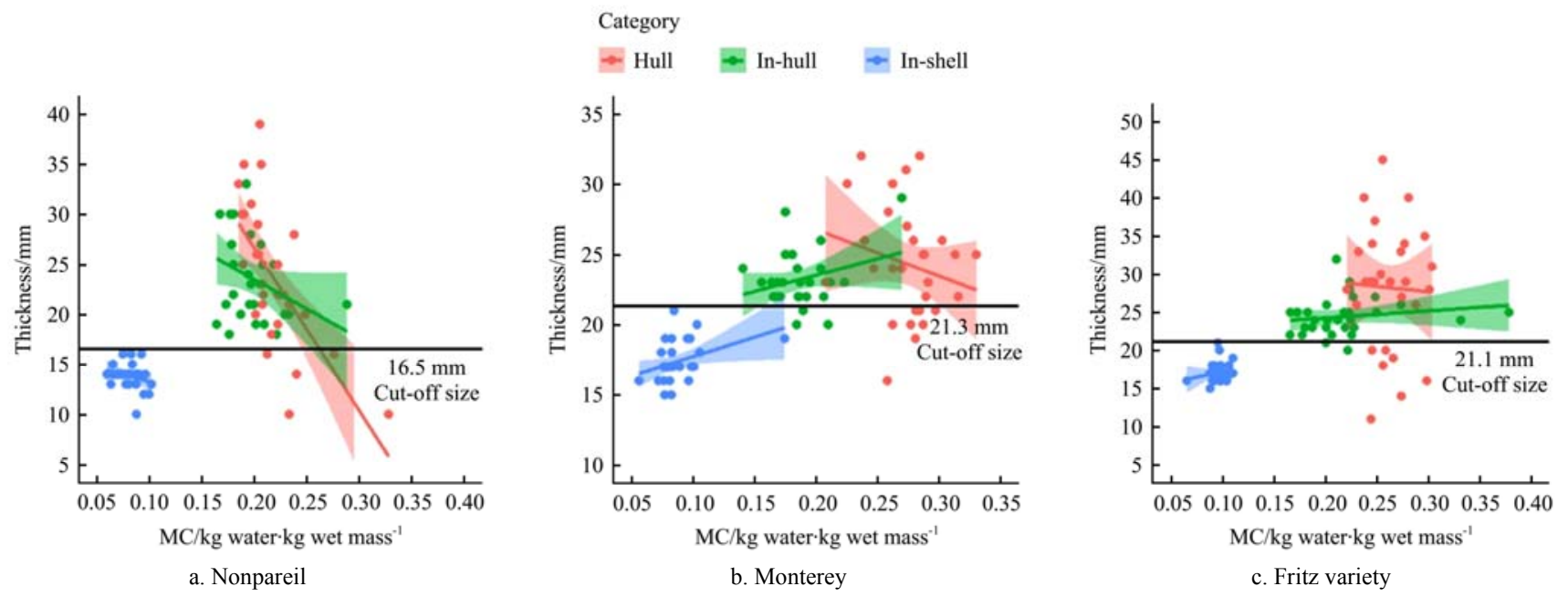

Figure 6 Distribution of almond thickness against moisture content, and cut-off size (black line) for Nonpareil, Monterey and Fritz variety

\subsubsection{Terminal velocity sorting}

As shown in Figure 7, when the critical values of the TVs were selected as $12.3 \mathrm{~m} / \mathrm{s}, 11.8 \mathrm{~m} / \mathrm{s}$ and $12.2 \mathrm{~m} / \mathrm{s}$ for Nonpareil, Monterey and Fritz varieties, respectively, the in-hull almonds and loose hulls could be $100 \%$ separated for Monterey and Fritz varieties. It should also be noted that for Nonpareil variety, 3.3\% of in-hull almonds would be lost in the loose hulls, while $13.3 \%$ of loose hulls were mixed with in-hull almonds. Although lowering the TV may avoid product loss, most of the loose hulls would then be mixed with the in-hull almonds, which would reduce the efficiency of sorting.
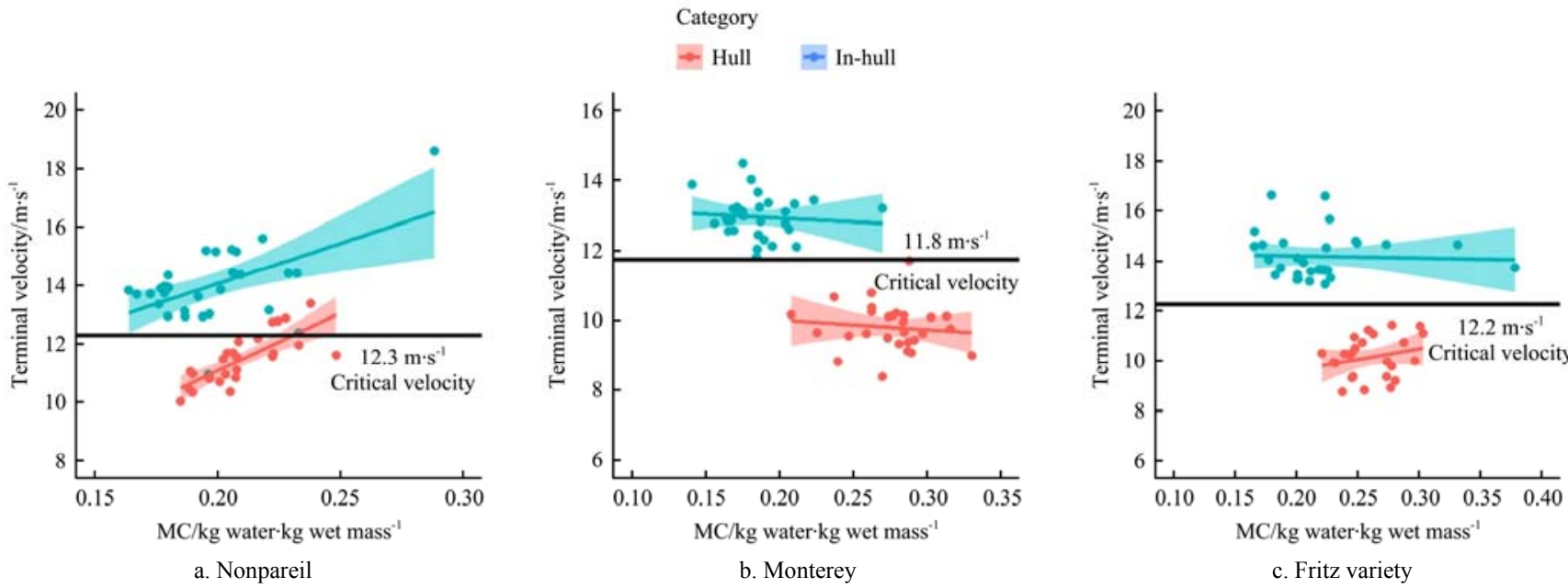

Figure 7 Distributions of terminal velocity of almonds against moisture content, and critical values of terminal velocities (black lines) for Nonpareil, Monterey and Fritz variety

After the TV sorting, the MCs of in-hull almonds ranged from 0.164 to $0.188 \mathrm{~kg}$ water $/ \mathrm{kg}$ wet mass with an average $\mathrm{MC}$ of $0.198 \mathrm{~kg}$ water $/ \mathrm{kg}$ wet mass for Nonpareil variety. For Monterey variety, the MCs of in-hull almonds after sorting ranged from 0.141 to $0.270 \mathrm{~kg}$ water $/ \mathrm{kg}$ wet mass with an average MC of $0.185 \mathrm{~kg}$ water $/ \mathrm{kg}$ wet mass. For Fritz variety, the MCs of in-hull almonds ranged from 0.166 to $0.379 \mathrm{~kg}$ water $/ \mathrm{kg}$ wet mass, and the average MC was $0.219 \mathrm{~kg}$ water $/ \mathrm{kg}$ wet mass. It was found that the distribution ranges of the sorted in-hull almonds were still wide, and the weight of hulls from in-hull almonds represents at least $30 \%$ of the total almond weight at harvest. Thus, de-hulling of the in-hull almonds will be necessary to improve the moisture uniformity and drying efficiency, and reduce the energy consumption and space need for storage and transportation.

\section{Conclusions}

Almonds harvested off-ground had much lower insect infestation percentage than the conventional on-ground dried almonds. The freshly harvested almonds had different maturity stages and resulted in three fractions, namely in-hull almonds, in-shell almonds and loose hulls, which had different MCs. Particularly, in-hull almonds and loose hulls had much higher MCs 
than the in-shell almonds at harvest, thus sorting of the three fractions before drying is necessary. A two-step sorting approach was developed. In the first step, the cut-off sizes of $16.5 \mathrm{~mm}$, $21.3 \mathrm{~mm}$ and $21.1 \mathrm{~mm}$ could be used to sort out the in-shell almonds by $100 \%$ for Nonpareil, Monterey and Fritz varieties, respectively, which were selected based on the almond thickness. In the second step, $96.7 \%$ in-hull almonds could be separated from loose hulls using the terminal velocities of $12.3 \mathrm{~m} / \mathrm{s}, 11.8 \mathrm{~m} / \mathrm{s}$ and $12.2 \mathrm{~m} / \mathrm{s}$ for Nonpareil, Monterey and Fritz varieties, respectively. Overall, up to $76.7 \%$ of the loose hulls at harvest could be removed, and only up to $3.3 \%$ in-hull almonds may be lost during the sorting process. The variation ranges of moisture in the in-shell and in-hull almonds were improved after the sorting and separation compared to the almond mixture. The research findings provided important information for the development of efficient sorting and drying methods for off-ground harvested almonds with improved processing efficiency, product quality and safety. Implementing the research findings should be helpful for addressing the urgent need in the almond industry and improve sustainability.

\section{Acknowledgements}

The authors acknowledge that this work was financially supported by the Almond Board of California. The authors also would like to give special appreciation to Guangwei Huang and Sebastian Saa from the Almond Board of California for the supports throughout the research process, also special thanks to Dr. Franz Niederholzer at Nickels Soil Lab, Arbuckle, California, who helped with arranging almond harvesting throughout the research process. The authors would also like to thank Lizhen Deng and Irving Rabasa in their research lab for their contribution to the projects.

\section{[References]}

[1] Geisseler D, Horwath W R. Almond production in California. 2018. Available: https://apps1.cdfa.ca.gov/FertilizerResearch/docs/Almond_ Production_CA.pdf. Accessed on [2019-11-05].

[2] 2018 California almond objective measurement report. USDA, National Agricultural Statistics Service (NASS), $2018 . \quad$ Available: https://www.nass.usda.gov/Statistics_by_State/California/Publications/Spe cialty_and_Other_Releases/Almond/Objective-Measurement/201807 almom.pdf. Accessed on [2019-11-05].

[3] King J A D, Miller M J; Eldridge L C. Almond harvesting, processing and microbial flora. Applied Microbiology, 1970; 20(2): 208-214.

[4] Schade J E, McGreevy K, King J A D, Mackey B, Fuller G. Incidence of aflatoxin in California almonds. Applied Microbiology, 1975; 29(1): 48-53.

[5] Campbell B C, Molyneux R J, Schatzki T F. Current research on reducing pre- and post-harvest aflatoxin contamination of US almond, pistachio and walnut. Journal of Toxicology: Toxin Reviews, 2003; 22(2-3): 225-266.

[6] Schatzki T F, Ong M S. Distribution of aflatoxin in almonds. 2. Distribution in almonds with heavy insect damage. Journal of Agricultural and Food Chemistry, 2000; 48(2): 489-492.

[7] Khir R, Pan Z, Atungulu G G, Thompson J F. Characterization of physical and aerodynamic properties of walnuts. Transactions of the ASABE, 2014; 57(1): 53-61.

[8] Chen C, Venkitasamy C, Zhang W, Deng L, Meng X, Pan Z. Effect of step-down temperature drying on energy consumption and product quality of walnuts. Journal of Food Engineering, 2020; 285: 110105. Doi:10.1016/j.jfoodeng.2020.110105

[9] Chen C, Khir R, Shen Y, Wu X, Zhang R, Cao X, et al. Energy consumption and product quality of off-ground harvested almonds under hot air column drying. LWT, 2021; 138: 110768. doi: 10.1016/j.lwt.2020.110768

[10] Ndukwu M C, Ejirika C. Physical properties of the African walnut (Tetracarpidium conophorum) from Nigeria. Cogent Food and Agriculture, 2016; 2: 1232849. doi: 10.1080/23311932.2016.1232849.

[11] Ahad T, Rather A H, Hussain S Z, Masoodi L. Physical properties of in-shelled walnuts and kernel effected by moisture content. International Journal of Chemical Studies, 2017; 5(4): 1753-1757.

[12] Chen C, Venkitasamy C, Zhang W, Khir R, Upadhyaya S, Pan Z. Effective moisture diffusivity and drying simulation of walnuts under hot air. International Journal of Heat and Mass Transfer, 2020; 150: 119283. doi: 10.1016/j.ijheatmasstransfer.2019.119283.

[13] Chen C, Upadhyaya S, Khir R, Pan Z. Simulation of walnut drying under hot air heating using a nonequilibrium multiphase transfer model. Drying Technology, 2020. doi: 10.1080/07373937.2020.1846552.

[14] Atungulu G G, Teh H E, Wang T, Fu R; Wang X, Khir R; Pan Z. Infrared pre-drying and dry-hulling of walnuts for improved processing efficiency and product quality. Applied Engineering in Agriculture, 2013; 29(6): 961-971.

[15] Chen C, Zhang W, Venkitasamy C, Khir R, McHugh T H, Pan Z. Walnut structure and its influence on the hydration and drying characteristics. Drying Technology, 2020; 38(8): 975-986.

[16] Thompson J F, Grant J A. New moisture meter could curb over-drying of walnuts. California Agriculture, 1992; 46(2): 31-34.

[17] Razavi S M A, Emadzadeh B, Rafe A, Amini A M. The physical properties of pistachio nut and its kernel as a function of moisture content and variety: Part I. Geometrical properties. Journal of Food Engineering, 2007; 81(1): 209-217.

[18] Altuntas E, Erkol M. Physical properties of shelled and kernel walnuts as affected by the moisture content. Czech Journal of Food Science, 2010; 28(6): 547-556.

[19] Gharibzahedi S M T, Mousavi S M, Hamedi M, Khodaiyan F. Engineering characterization of Persian walnut and its kernel (Juglans regia L.) for obtaining high quality produce. Quality Assurance and Safety of Crops and Foods, 2013; 5(2): 145-156.

[20] Gupta R K, Arora G, Sharma R. Aerodynamic properties of sunflower seed (Helianthus annuus L.). Journal of Food Engineering, 2007; 79(3): 899-904.

[21] Razavi S M A, Rafe A, Akbari R. Terminal velocity of pistachio nut and its kernel as affected by moisture content and variety. African Journal of Agricultural Research, 2007; 2(12): 663-666.

[22] Khir R, Pan Z, Atungulu G G, Thompson J F, Shao D. Size and moisture distribution characteristics of walnuts and their components. Food and Bioprocess Technology, 2013; 6: 771-782.

[23] Ozdemir F, Akinci I. Physical and nutritional properties of four major commercial Turkish hazelnut varieties. Journal of Food Engineering, 2004; 63(3): 341-347.

[24] Galedar M N, Tabatabaeefar A, Jafari A, Sharifi A, Mohtasebi S S, Fadaei H. Moisture dependent geometric and mechanical properties of wild pistachio (Pistacia vera L.) nut and kernel. International Journal of Food Properties, 2010; 13(6): 1323-1338.

[25] Aydin C. Physical properties of almond nut and kernel. Journal of Food Engineering, 2003; 60(3): 315-320.

[26] Khir R, Atungulu G G, Pan Z, Thompson J F, Zheng X. Moisture-dependent color characteristics of walnuts. International Journal of Food Properties, 2014; 17(4): 877-890.

[27] Wang Z, Sun J, Chen F, Liao X, Hu X. Mathematical modelling on thin layer microwave drying of apple pomace with and without hot air pre-drying. Journal of Food Engineering, 2007; 40(1): 39-46

[28] Chen C, Khir R, Shen Y, Wu X, Ning Z, Niederholzer F, Pan Z. Energy and quality analyses of off-ground harvested almonds under hot air column drying. 2020 ASABE Annual International Meeting, Omaha: ASABE. 2020; Paper No.2000193. doi: 10.13031/aim.202000193.

[29] Galedar M N, Jafari A, Tabatabaeefar A. Some physical properties of wild pistachio (Pistacia vera L.) nut and kernel as a function of moisture content. International Agrophysics, 2008; 22(2): 117-124

[30] Mirzabe A H, Khazaei J, Chegini G R, Gholami O. Some physical properties of almond nut and kernel and modeling dimensional properties. Agricultural Engineering International: CIGR Journal, 2013; 15(2): 256-265. 